\title{
Alone But Together: Exploring the Possible Barriers Impacting Learners' Feeling of Belonging in a Further Education Networked Learning Group
}

\author{
Anietie G. Ukpabio \\ 1.Doctoral Researcher of PhD in E-Research and Technology Enhanced Learning Lancaster University. \\ Lancaster, UK \\ 2.Business Analyst at IBM Client Innovation Centre. Leicester, UK
}

\begin{abstract}
This interdisciplinary study uses the lenses of post-structuralism and anarchism to reconsider the issues of belongingness within a further education networked learning group. This is because post-structuralism problematises the notion of belongingness from the stance of group representation which may well imply that the 'self' is fragmented; In fact, post-structuralism considers the idea of group representation to have been misconstrued from the dimension of a linguistic construct. Similarly, anarchism rejects the idea that part of a group can represent the whole of the group; individual autonomy is paramount than group autonomy and the former shapes the latter.A narrative inquiry was used to explore the barriers and how conflicting ideas about the 'self' in group representation evolves and survives or how the 'self' struggles and dies. The experiences of four lecturers were collected and analysed and an argument was put forward towards a critical ethical consideration regarding the notion of networked learning and learners feeling of belonging. The emphasis was not to attempt to generalise, but to typicalise certain issues that should not be accommodated within the utopian notion of online learning groups and communities.
\end{abstract}

Keywords: Belongingness, belongingness, post-structuralism, further education, online communities, learner identity, community of practice, networked learning

DOI: $10.7176 / \mathrm{JEP} / 10-9-16$

Publication date:March $31^{\text {st }} 2019$

\section{The habitus of networked learning and its contested challenges}

The hassle of distance, independent and networked learning projected towards widening understanding in any field can lead to fluctuating feelings of belonging, acceptance and confidence-mentally and socially. Introduction to new concepts, norms, and ethics can lead members/learners to question their stance within their various social contexts.

This study attempts to combine two notions, which are the notions of how people are represented (as regards to their identity) and represented (as regards to the changes and dynamics of collective membership) within the meaning of their entanglement in groups. So, in this example, I am interested in how these representation issues are being worked out as regards to learning societies. To untangle some of the notions embedded in the utilisation of community models of learning, two theoretical sides of view were deployed, which are complementary. I utilized concepts from post-structural theory to scope the issues of identity representation and also anarchist theory to problematise the concept of group representation of individual member interests. These two theoretical attempts possess a tradition of being doubtful of the manner that social norms prohibit differences which exist in individuals; and also I want to proceed this impulsive mistrust of representation to apply it within a context of a further education college networked learning group.

To begin with, I draw on the ideas of representation present within the groups, looking at it from each person's view back out towards individual collaboration. Psychology has already provided a panacea of restraining manner of thinking about participation and group membership. Allport (1920) states that there is no group psychology that is not necessarily an individual psychology and this position has arguably changed slightly. This reductionist perspective has remained principal despite obstacles and it creates issues when questions about how individuals communicate with the society and not just only communities of learners are asked. There is a transparent effect that individuals seek permission to take on group norms when they join groups and also that despite this, their own accomplishment of identity remains constant (Katz and Earl, 2010).

Similarly, in a related manner, anarchism is deeply doubtful of each member's contractual form of group membership, in which members of the group knowingly and freely negotiate a compromise, forgoing the pursuit of some wants so as to achieve others, but remaining necessarily constant by their interaction with other members of the group. Anarchism proposes that there is more going on collectively than individually, but it does not support the need to negotiate away parts of the "self" in this manner. Instead, membership includes (or should include) an identification that is imaginative with the complete information of the wants and lives of others (Jackson and Temperley, 2007). Along this line, new possibilities for identities may emerge. Also, and less positively, it is 
possible that members are being coerced to interact genuinely by having to refuse aspects of themselves that they feel are essential due to power asymmetries in the group. To express this differently, the "self" itself is at risk in group membership (McNay, 2013). This forms one of the underpinnings upon which this study is problematised on.

\subsection{Study aim and questions}

To reinforce the discussions above, this study aimed to explore the possible barriers impacting learners' (FE lecturers') feeling of belonging in a further education networked learning group. The study objectives are intertwined within the main and sub research questions which were to begin with a question that explores what aspects of lecturers' motivation make them join a networked learning group in an HE-within-FE (Higher Education within Further Education) setting? Beyond this question, it became imperative to exploit the benefit of such a relatively encompassing question by accompanying it with important follow-up questions which supported the formation of themes and reinforced the narrative thread section of the study. The questions were:

a. How do FE lecturers attempt to integrate and assimilate into a networked learning group?

b. In a network learning group, do lecturers attempt to coerce and punish others?

Overall, post-structualism and arnachism theoretical frameworks were useful towards understandings of the notion of the self and the group.

\section{Review of relevant literature}

\subsection{Networked learning communities, identity and subjectivity}

The relationship between technology and human subjectivities has given rise to numerous different 'figurations' (Glenn and D'Agostino, 2008). Taking up of technological identities (biologically - a female presuming to be a male online or vice versa) or (psychologically, an introvert becoming an extrovert), avatars, technological prosthetics is a captivating aspect in its own. In spite of this, this paper revolves around an area which discusses beyond the horizons of opinionated subjectivity and towards complementing theoretical territories of poststructuralism and anarchism.

The 'new' identity politics envisioned by Griffiths (1995) does not disqualify the concept of an individual man or woman - eliciting the right of his/her own free will from forming opinions regarding identity as well as participating in the identity aligned with others. Allowing the personal humanist subject 'in charge' of their identity helps psychology; although, as a field, it remains comparatively abreast on altering the notion of identity. Hence, the supposition of how individuals discuss or agree towards group identities, morals and customs remain untouched. This consequently helps in generating comfortable conceptions of learning communities - online or otherwise to prosper as well as stay unchallenged.

Desirably, a theory of identity which indulges in the concept of it being comparatively unstable over time, interpreted as an exterior source of subject's will power, thereby, proving the individual's admission as well as existence in a segregated social group as complicated and contradictory is an essential debate in learning communities. Such a vision of an individual subject and of subjectivity has been termed as 'precarious, contradictory and in process' under the post-structuralist theory (Wetherell, 2008). However, it is insufficient. Where post-structuralism emphasises that the subject is produced historically, it is feminist post-structuralism that provides the concept of the subject being a place of continual conflict. The political significance of ignoring a certain belief in an important bias is that subjectivity then becomes susceptible to change (Wetherell, 2008).

However, if subjectivity on entering a learning community or smaller sub grouping is open to wider level to inscription, then it may also be open to inscription from the smaller sub groupings. On an occurrence such as this, the individual's entry would not be classified as a wilful act or even negotiating membership of the cultures and customs of that group. It is then a place where the identity of the joining members are etched and proscribed. Any sort of identity in a group becomes a gift of 'conflicting and contradictory' (Wetherell, 2008) social converse being conducted in a group. How would this alter the perspective of participation as well as communication within learning communities? At this point, an argument could be put forward that individuals generally understand the social norms when joining a learning community or even that they are at a learning community because they share common beliefs. However, these assumptions can be challenged as participants can be rejected on the range and depth of subject positions in a learning community. Obviously, there have always been contradictory elements in a learning community which if not fully comprehended, are at least reacted to.

Overall, two broad options about the micro-processes of learning communities have been deduced for a debate after closely articulating the concept of subjectivity through the lenses of post-structuralism. Firstly, adjusting as well as exploiting the potential of various styles of participation (between different as well as within individual members) becomes an issue if individuals are allowed to alter their identity according to their desires. Secondly, communitarian perspectives on learning communities must be considered in addition to how an educational community helps in creating, bestowing and controlling the subjectivity of its members in customs which are dissimilar to the voluntarist context. 
Such participation in learning communities invokes a sense of liberty among the wishes of the individual. During the first concept, the individual on its own, forms and declares their preference of identity within the group setting; whereas during the second conception, it is entailed that the normative discourses limit as well as obscure the desires or identities of the individual. The thought of consent has been markedly improved as well - clearly implying that any 'good' alternative learning community would be in a constant search of promoting and gaining creative power from identity transformations and look after the social discourses which inadvertently limit the prospects of identity proliferation. Undoubtedly, it would be at a loss to dissert the argument at such a stance if the objective of this study was to invoke stimulating ideas regarding communities (Kahler, 2015).

Braidotti (1996) believes that power is unconstructive as it forbids and confines. However, I argue that it may be constructive since it authorises and facilitates. The balance can be negotiated between the two extremes of power by designing more politically to align with the concept of subjectivity of power and desire. This idea conceives the topic as a continuously evolving theme, which is quite co-extensive with power as well as resistance (Hodgson, McConnell and Dirckinck-Holmfeld, 2012).

It can be ascertained from the aforementioned notion that a learning community can be in a constant tussle of checking, interpolating and decreasing the impact of negative (potestas) to the positive (potentia). However, there lies another argument that in order for a learning community to form communities and discover the notion of collective desires; it may intentionally limit potential by conjuring potestas. The unconscious assumption of freedom being equal to liberation or emancipation should be debated within such a model. It invokes the different perception of the role and worth of differences in groups. Plus, the uneasiness associated with the ethics of learning communities would be at the same level as that of the micro-processes (Dohn, 2014). The related issues of ethics is briefly discussed in the gaps identified between literature of this genre; however, the next section of the of this paper talks about a broader level analysis of individualism and its interaction with the ideas of community within anarchism.

\subsection{Networked learning communities and anarchism}

Amidst the utopian assumptions that surrounds the notion of belongingness within networked learning communities, there exits various quandaries associated with recognizing the ideal communities in which members enjoy both, the sense of autonomy as well as belonging; even in virtual learning communities which have been formed by academic or corporate institutions as part of their activities (Vuković, 2015).

Anarchist beliefs can be useful in reformulating 'learning communities' and raise significant questions regarding the advantages that information technology poses or gives way to the typical ethical issues as any other developed and fragmented community. It should be highlighted at this point that anarchism is basically a heterodox tradition by design and must be discussed as 'anarchisms'. Yet, the thinking of anarchists described below tries to explain notions that if not all but most of anarchists would agree with.

Anarchism places a paramount value on individual autonomy, where most anarchists believe that none of the individuals should be made to obey the collective customs or decisions (Wetherell, 2008; Marshall 1993). Certainly, the rejection of authoritative principles as well as hierarchical representation has been employed by anarchists historically (Kropotkin, 2002). More importantly, anarchists have been misconstrued as being mad; however, they are not obtuse. It is an ongoing argument within the anarchist's belief of finding the equilibrium between ensuring complete individual autonomy and maintaining a community. The problems associated with regulating behaviour have been more found in anarchism as opposed to utopian mentalities (Vuković, 2015).

The issue this introduces at this point is a society where members are not bound by any limitations or rules; what should be done if an individual's choices limit the opinions of others or results in a harmful discourse. The assumptions of anarchists rely on the fact that by removing the distracting influence of hierarchy and inequality, there would be lesser reasons of such behaviour. However, they do not realize that passions and conflicts form the basic elements of human nature. Yet, prescriptive or institutionalised ways of reprimanding violence, maltreatment, and other forms of anti-social behaviour, or to ensure that following of different rules and procedures, are considered to make the consequences of such outcomes much more destructive than doing nothing, or rather simply to permit individuals to figure out these things among themselves (Suoranta, 2011).

There are various much more constructive as well as collective ways of resolving such issues which consist of 'leaving alone', exile, community juries, or the effects of societal customs and disapproval as opposed to removing each and every kind of individual as well as institutional authority. The problems associated with constructive methods have been highlighted by anarchist in their debates (Marshall, 1993), while the micropolitical post-structuralist (May, 1994) have also addressed this issue; yet, the solutions suggested are never taken seriously. Such views may be considered as a fatal flaw; nonetheless, it forms as well as justifies the basis of anarchist principle. Social practices are always deemed as arguable, temporary and can be re-negotiated if not institutionalised. It has been established that an ideal anarchist community is constantly evolving where communal as well as individuals can freely determine their needs and desires which are mutually acceptable as well as consensual for better social relations. 
This utopian perception would not be satisfactory to those against the liberating possibilities of 'learning communities' since it is very debatable if such solutions hold a potential in a community which has been formed on the notion of pre-defined institutional regulations established by academy or corporation beyond the hands of common people of the community. Indeed, the ideal community of an anarchist is the one which is voluntaristic; where people can freely come and go by and the entire community would exist as long as it serves the consensual or self-defined requirements and desires of the members. The institution used for this study restrains and does not permit such learning communities even virtually due to its structure, stakeholders and quality assurance or simply the apparatus of assessment, and other intricate factors that words cannot properly articulate. Furthermore, the unequal distribution of power in the relationship of a college and learner and similar is the case when mediated by information and communication technology or re-acknowledging the tutor as a facilitator.

Furthermore, the institutionalised setup of most learning communities proposes the type of identity which is appropriate to learners and teachers. In a staff networked learning community, such identities are resiliently associated with the hierarchies as well as the co-modified depiction of the management itself. An anarchist views the notion of group representation within learning communities with a reasonable scepticism (DeLeon, 2008). The obscuring of difficulties associated with group ideology and representation as well as the hidden types of power introduces a utopian perception and makes it more susceptible to surprising members of the group. On the other hand, it is more of an intricately built communal ethics formed on the basis of a precautionary insight deduced from the arguments raised within post-structuralism and anarchism rather than simply naming it as abandonment.

\subsection{Can post-structuralism enhance anarchism}

What implication does the theories of post-structuralism and anarchism mean to this study? Being initiated from two entirely different perspectives, it pinpoints towards the similar outcome that results from individuals who gather in pursuit of achieving common or at least harmonizing aims. It would appear that some alluring speculations for critical pedagogy can be established if the two traditions are brought together. This study tends to assume that post-structuralism illustrates an essential anarchic sense and may offer another academic basis laid for progressing of anarchism extending well beyond its 'Enlightenment Roots'. Anarchism in itself also offers a set of political and organisational policies which are in concordance with the poststructuralist notion of ideologies as well as collective movements (Portwood-Stacer, 2010; May, 1994). Nonetheless, the purpose of this study is much more limited than a type of poststructuralist anarchism - this was sought with the sole intention to explore the possible barriers impacting learners' (FE lecturers') feeling of belonging in a further education networked learning group. Aspiring for a much constructive or fruitful stimulus for discussion; the literature would be concluded, in spite of rejecting the utopian ideologies of networked learning communities; certain ethical questions could be raised to investigate the actual occurrences of learning communities with respect to identity and ideas of consent (Hoyt, 2013).

The question is what would be the possible extent in an institutional setting to attain a freely or wilfully negotiated networked learning process. From an anarchist's perspective, the destructive influences of power as well as hierarchy will evidently compromise institutions established for the collective control. Also, anarchism would refuse since there would be a 'legitimate' authoritative power associated within the lecturers. From a poststructuralist's perspective the procedures that form identity which is out of individuals control are nonavertable in a learning community instead such communal simply offer particular discourses as well as sites of subjectivity. Also, post-structuralism would have problems associated with the idea of freely negotiated society since subjectivity would be seen as a dynamic process and as an outcome of the intermingled desires and discipline, certainly not as something which can discuss the idea of authority.

Most probably, the proposition by Mueller (2012) would be the closest for an anarchist to classify as an ideal model; which includes people freely choosing each other in pursuing learning goals but limitations would exist in terms of making judgments regarding the learning process beyond the scope of judgments made by learners. Such a utopian stance seems to exist only in a different society than what is inhabited. The ideals pursued by members need to be identified, their origin must be recognized and their operation in terms of an intermingling of desires and networks of power within the community must also be established. The range of subjection positions present in the learning communities must be explored and it must be analysed if they are exploratory, limiting, oppressive or extending (Adams, 2013). It could be a fruitful inquisition through which it could be analysed how the experiences as well as identities of some members help in achieving other members desires - is it absolutely certain if these are mutually inspirational or it occurs simply by certain members? And most conclusively, to what extent could an individual's desire be accommodated within a society? If constraints exist, can these be justified by the gains for each member?

It would be unintelligent to simply assume that such questions would result in conclusive or candid answers; however, raising such questions would prevent from developing or nurturing the blind faith that exists about learning communities. 


\section{Methodology and Method}

It is arguably commonplace in educational research that the difference between method and methodology is easily disregarded at either a theoretical or a practical level. Such disregard causes researchers to ignore the fact that methodology signifies the rationalisation of approaches employed in eliciting research whereas method denotes the approaches employed in conducting research. It is this type of complementary relationship that exists between method and methodology that this study's method was built on.

\subsection{Context of the study}

The research setting took place at a further education college that predominantly teaches further education courses and higher education courses in association with its partner universities. The college occupies six campuses which are located in the capital of England (London) and does not possess the power to award academic degrees other than diplomas (at level 2, 3 and 4 from Pearson Edexel, Gateway and City \& Guilds) and NVQs (at level 2, 3 and 4 from Pearson Edexel, Gateway and City \& Guilds). The college claims to be inspired by the kind of networked learning community cultivated by the Higher Education Academy (HEA) called the Flexible Learning Community of Practice (FLCoP). This replica community formed by the college called Further Education Community of Practice (FECoP) is aimed at connecting members of staff who share an interest and an enthusiasm for developing and using robust approach of teaching, learning and assessment to modern best practices and thinking from across various disciplines. According to their quarterly magazine titled "Telling Through TEL" it is made possible via a vibrant and collaborative process of knowledge sharing and development in the form of dialogue forums, webinars, and follow-up meetings of physical presence (not via video conference).

\subsection{Method (Study design)}

This study focused on 4 out of a few lecturers who are members of the FECoP and were anonymously referred to as Carl, Jake, Jane and Sarah while an investigation was elicited to explore their experience of engaging with the networked learning community (FECoP), along the lines of the study questions. The account of the settings in which they connect and interact with other members of the group is explicitly explained in the findings section of the discussion. For the data collection, one qualitative research methods was employed, which was interview. The structure of the interview was based on a semi-structured format which followed the pattern of thematically designed, sequentially suggested questions, and were modified willingly in concordance to the responses recorded during the interview by the interviewer. These interviews were recorded and scrutinized numerous times during transcription.

Before the interview of the lecturers, the research was described and the participants were reassured of their anonymity including identifiable names, statements, location and time. Their consents were genuinely obtained in a written and signed format and a very easy and transparent opt-out process was explained and administered. Various interviews were carried out with each lecturer; the initial interviews were physical interviews whereas the majority of the follow-up interviews were conducted virtually. Initial interviews which were conducted physically took up more time (typically 30 to 60 minutes) since the purpose was to fully comprehend the understanding of the lecturers' experience.

The data analysis took place in three stages. During the first stage, the settings of FECoP forum were looked at and possible questions were determined for the interview. The second stage included the interpretation of audio recordings (recorded during the interview) as well as deciphering the interpretations, while conducting a member checking process to affirm the meanings that were construed with the interviewees, and avoiding the inapt and inadvertent understandings of the data obtained during the interviews (Cresswell, 2009). The third stage included categorization of the patterns that emerged as a result of the three subjects. The similarities and differences observed according to the three topics were translated and interpreted whereas interrelations were also made.

\section{Discussion}

\subsection{Real meets virtual: An identity clash or identity merger?}

Identity happens to be an interesting area of much consideration and debate in networked learning environments (Ryberg and Larsen, 2008). For most scholars, the evolution of networked learning comprises of transitioning from the known and comfortable traditional practice of identities as well as activities to a novel engagement where both, identity and activity need reconstruction and re-negotiation. As previously argued in O'regan (2003), scholars may be endangered by such processes, especially due to the need of editing or augmenting their identities (Boon and Sinclair 2009). There are tendencies of open resistance towards participation in an online environment by even colleagues of the same institution, irrespective of their differences in age. As offline and online learning environments can sometimes be intertwined learning environments, it is possible for a lecturer to be occupying or concurrently spanning between the two worlds.

Whilst Carl is experienced and close to retirement, such intricacies, complexities and associated challenges to identity as well as ways of thinking and practicing is common and can be a significant barrier to engagement in 
networked learning environments. Symbolically, an individual - lecturer or student need to dislocate from customary frameworks and networks for teaching as well as learning in order to immerse in a networked learning environment (Anderson, 2009; Wood and Smith, 2005). For some lecturers (like Jane), who discharges the same mandate of leading the discussions during the face-to-face meetings of FECoP sessions, this can be quite a confusing and foreboding process:

I experienced a dislocation in my pristine role of a moderator/discussion lead in the FECoP. Upon discussing this feeling with a colleague, he was experiencing similar uncomfortable as well as slightly nervous sentiments. We later realized that this use of technology to do what we usually physically do whilst bantering each other and drinking coffee in a single room dislocated us from our original, preestablished and disciplinary "CoP". We feel isolated in a way but it makes sense. The FECoP is clearly a new environment in any case. I had imagined this transition to be an easy one - simply by applying my knowledge to a distinct context - but it was not as easy. I foresee that there is a lot more associated to it in order to accommodate people like me. (Jane's interview, 8 November, 2017)

It is understandable that in order to work effectively in an online capacity, one must make a willing and conscious effort to engage as well as accept the challenges and opportunities proposed by the networked learning. Such virtual haziness and renegotiating the identity, for instance, concurrently offers and threatens the lecturers with their probable amends in role, extent of engagement and relationship among themselves, Jane's narrative implies.

Relationship with my colleagues is quite different. I am often perplexed by the difference in their identities when on the FECoP platform online. Nonetheless, I am equally guilty of being different when online. It happens to be a new environment for all of us, I assume. However, I think the virtual world is home to the younger or tech savvy lecturers who are so into tech and gadgets. In a non-derogatory way, "the geeks". Whereas I find it challenging, yet I still perceive it as an opportunity. It can be quite odd at various instances. It is not unpleasant mostly - even though it can be - yet it needs a lot more effort, a distinct type of engagement, a different set of knowledge, another relationship as well as language. And

I deduce I am learning all of that even now. (Jane's interview, 8 November, 2017)

The transition of online academics requires re-analysing and probably redefining academic identity. During this conversion, the academics are found in places where role, activity and identity are all in doubt, and eventually need re-analysing and refocusing. Encounters with as well as within networked learning environments questions educational and professional identity: for instance, how should lecturers represent or portray themselves in networked learning environments? How would lecturers' identities be negotiated or re-discussed during the process? How will lecturers thought processes or ways of practice be conversant or confronted? These questions continue to remain worthy of if possible, answering in all its entirety.

\subsection{Language becomes a barrier and an enabler}

The use of notions that describe events that occurs online exposes how the usual occurrences are conceptualized. Analyzing from the viewpoint of someone striking various key strokes of a keyboard, watching the screen and moving the cursor/mouse towards transiting through this phase of learning, a complicated notion is subconsciously being invoked into place. The occurrences that transpire in these engagement areas must be properly analysed. Such a notion entails that this novel medium of technology is not simply a transporter for content as some people might misconstrue it to be (Turner, 2009); instead it is a place where identity as well as activity are developed with the use of textual communication or more. However, it requires certain inevitable modifications which have been illustrated from Sarah who is at the midpoint of her academic career at the college.

Quietness or silence is not only perceived differently online, it has also been colloquially entitled as 'lurking', meaning to remain calm and hidden - although, it has attracted negative inferences in anticipation. Since the lecturers seem to be experienced, she must have had extensive associations for her decisive deductions. The example describes how this perspective can be a facilitator thereby enlarging the current comprehension. For certain lecturers, challenges highlighted in this report might be a barrier, especially with its use being associated with negative perceptions. Moreover, some of the lecturers might also be influenced by the new perspective thus provided, with its effect being a threatening or dismantling one.

Another lecturer can consider the online connotation of the word 'lurking' as a benchmark of a definition or reference. This lecturer could perhaps hold a new perception of the word 'silence'. Questionably, the notion of lurking for the experienced lecturer and the notion of speech acts for the inexperienced lecturer could scaffold a comparable novel scientific viewpoint of the usual notion of the word 'silence' as well (Wood and Smith, 2005).

New expressions, new connotations and different uses have a potential to strike a change and aggravate towards a novel approach on anything in the pre-existing catalogue. During an encounter, a response may be generated which can be easily overlooked. Another narrative from a Jake, an early academic describes the transformative 'point of encounter' response which is a relevant theme to the deliberations made in this study.

Sometimes I post things. This can either be starting a new thread, replying to an existing thread or replying 
to a comment within a comment. I don't always expect a response from the things I say online because it could be open-ended or it could just be that I have successfully won an argument. I would not imagine the same in a face-to-face situation as I would definitely find the silence of a colleague offensive, awkward and rude. (Jake's interview, 6 November, 2017)

\subsection{Struggle with time}

When discussions about networked learning are brought to scrutiny, time is also an essential factor similar to identity and language which is undeniably shifted. It can be argued that time happens to be among the first of things which undergoes transformation when using online spaces. Lecturers who work or participate in networked learning environment feel a variation in their relation with time which is often described as a increase or decrease of either time or/and the speed of activity. The narrative of Sarah respectively shows that on entering the virtual world a change of perspective about the notion of time, speed as well as activity is required (Katz and Earl, 2010).

\subsection{Study discussions}

The internet, information technologies and a mixture of synchronous and asynchronous exchanges helps lecturers in being continuously networked. For example, social media platforms are all quite everlasting and perpetual. Most lecturers arguably happen to be virtually ubiquitous, yet at a significant cost. At this point the barrier as well as the enabler; the opportunity as well the challenge, happen to intertwine. The most usual complaint among lecturers is regarding the extent of time and effort consumed in being online. Such a viewpoint genuinely causes a limitation in constant participation and belonging (MacKeogh and Fox, 2009). The primary interest of this study oscillates around this transformation of perception in FECoP and the sort of psychological changes these lecturers need to negotiate in order to perform efficiently within online spaces.

Furthermore, there is a continual pressure to stay online as well as available. Be hasty in responding to the needs of colleagues, and stay updated. Time in a virtual world is inherently a quick time. Straggle - which is a decrease in speed and/or association, which can also be termed as slow time - is not satisfactory and can inculcate frustration for some lecturers. It can be closely linked to their requirements of 'coping'. If the lecturers are not fast enough, it can lead to an experience and perception of their own lives as 'straggle in the real world. In this way, the virtual can humiliate the real by making it seem uncoordinated, slow and isolated. It is not unusual for lecturers to express their need of always staying online and be guilty for functioning in the real world. Such statements can however cause others to avoid the opportunities associated with networked learning environments thereby highlighting only the negative aspects of it (Trauger, 2009).

Paradoxically, the same procedures can cause the lecturers to make quite measured communications than the ones they make in a face-to-face meeting since these responses need to be typed rather than said. The test for lecturers is to find the equilibrium between the demands of transformed time and the opportunities it offers by facilitating as well as encouraging them to learn is often an ongoing concern. In order to productively manoeuvre and contribute in FECoP platform, the lecturers must elicit the modification from contemporary ways of real idea of time to the novel virtual conceptions. This transition demands the academics to rekindle and re-evaluate their relationship with time on a personal as well as professional level. It is proposed that it is significant to ascertain the different choices lecturers may have with respect to time specifically in the synchronous/asynchronous facets, which may decrease the limitations to participation and belonging; for instance, through less commitment or more commitment (Savin-Baden and Sinclair, 2011). A feeling of guilt has been felt at the lack of participation which was not discussed in the sections above. The last example also proposes guilt at over-commitment. The fact that posts are visible to all the members of FECoP community would make constant postings or the lack of it an effect to the group members - and indeed, the idea of interaction has been rendered quite complex since a post can have various negative connotations and inference. Although a lecturer that constantly posts may feel guilty of having a dominant voice over those that seldom posts. Likewise, a lecturer that seldom posts may feel guilty of undercommitting to the endeavour of sharing best practices on FECoP.

As with other facts of transition and change, interaction can be viewed as an enabler, a limitation or both. Lack of known signs, processes, and signals; networked learning on FECoP demands a different mindset of willful adjustment, engagement and participation. Like identity, language or time; proficient engagement in the FECoP platform depends on lecturers' candidness or adaptability in learning novel process of thinking, being and practicing.

\section{Findings}

As stated in the methodology and method section, four lecturers named Jake, Carle, Sarah, and Jane participated in the study. The interview of them was geared toward understanding the barriers impacting the learners' feeling of belonging in a further education networked learning group. The interview transcripts in section 5 (Discussion) show the responses of the lecturers. The study did not involve many participants and the findings were based on the replies by the four lecturers. For this reason, interview transcripts are found in both the "findings" and 
"discussion" parts.

The following are the findings presented in brief because they are well-covered in the next section of the paper. It was found that real interaction and virtual interaction cause identity clash and confusion to all those involved. This means that the role, identity, and work of lecturers continue to change as long as principles of networked learning receive endorsement in any learning institution. See one of Carl's responses:

I think that my daily routine is split into two categories. This implies that I usually teach students in the classroom within a physical space and interaction and during my CPD hours, I log on to the college's FECoP community and teach and learn by interacting with colleagues (both senior and junior). Whilst I am the same individual within these contexts, I still often feel that I have dipped my hands in two different pies. One being the real world I teach in within the classroom and the other being the online environment which I interact with to learn as well as share my practice. When I reflect on my day, I feel like these pies don't fit each other. Although, this feeling is rarely critical in any manner. I think it may be just me being my own worst critic. Also, I was born in the 60s but I still don't think that it is the reason for my estranged feeling. (Carl's interview, 6 November, 2017)

Language is a barrier and an enabler at the same time.

I think regarding speech acts - although I have now known these for more than three decades, I have a new perspective of these... This issue has elevated online, with the entire notion of lurking and being conscious of the power structure as well as the other effects such as the durability of an online message. (Sarah's interview, 7 November, 2017).

There is struggle with time when it comes to networked learning.

I have been observing a matter with time, especially the way I manage it, or what I expect from others in using it and the way this networked learning influences my view of time. I believe I will have to step back and re-evaluate the entire situation. I have a good comprehension of time and the extent of things I can conduct in less than an hour when I am in the real world. However, when I am online - less than an hour seems to be completely meaningless as I feel I can always do my tasks whenever I feel like during the day. (Sarah's interview, 6 November, 2017)

The internet, information and a mixture of synchronous and asynchronous exchanges facilitates networking amongst lecturers. Lecturers are also pressured to be online and available.

I sometimes feel like some silence is needed or perhaps we should have a minimum and maximum quota of contribution on FECoP. I don't want to be seen as the person that is always talking and having something to say online. I don't want to be perceived as if I think I am smarter than my colleagues. If we have a quota, our post frequencies or total would be equal and the feeling of guilt would be subdued. (Carl's interview, 6 November, 2017).

This generalises the fear that network learning; as much as it helps in learning, it brings problems along with it.

\section{Conclusion}

As demonstrated within various sections of this report, intricacies posits within various elements of networked learning platforms. Such platforms of transition and transformation - identity, engagement, time and language as highlighted throughout, can be seen as both; limitations and enablers. It is the position and attitude of the lecturers (group members) that proposes whether these platform (FECoP) would be embraced as opportunities or challenges or both (O'regan, 2003). It was noted that the narratives of lecturers are variable: their communication, the way they interact with one another, their relationship with time and even their comprehension of themselves happen to be in an almost continual flux within the networked environment (FECoP). In order for lecturers to perform efficiently in a networked learning platform, the lecturers should accept their alienation with the virtual environment and significantly find a niche for themselves in it. The narratives of the lecturers showed that they still choose - intentionally or otherwise - to imitate the real world in the online world instead of liberating themselves from the contemporary and familiar to form new constructs, selves, relations, and chances for engagement. It might take time to conquer the strangeness associated with online spaces and completely embrace the opportunities offered by it. Academics that cannot acclimatize would be able to see their progress halted due to these barriers. Those who adjust can definitely find that the self- same limitations once modified can make them enablers; providing them with new horizons for communication and participation in networked learning, beyond FECoP (Alghamdi et al, 2016).

It is difficult to classify the academic identities of lecturers within a networked learning group. For example, Sarah is a discussion lead, moderator, researcher, lecturer and mentor for trainee lecturers. She clearly mingles and learns with people that have originated from various generations, she needs to find appropriate methods of interacting with this diverse group of members. Like most experienced lecturers, Carl is emerging from the traditional settings of learning yet with part of him being held in the previous world.

Although I state the aforementioned recommendations in a seamless manner, much remains to be explored beyond the notion of Sarah's fluctuating role, or Carl's distinct worlds of real and virtual or Jakes distinction of 
meaning of online silence. Further prospect for comprehension and research would need to examine what the application of some of the suggestions offered by anarchism would yield within FECoP and the implications for group and individual identities (Edmundson, 2007).

It would be unintelligent to simply assume that such prospects would result in conclusive or candid answers; however, attempting such prospects would prevent from developing or nurturing the blind faith that promotes the utopian notion surrounding networked learning communities.

\section{References}

Adams, M. S. (2013). Art, education, and revolution: Herbert Read and the reorientation of British anarchism. History of European Ideas, 39(5), 709-728.

Alghamdi, M., Regenbrecht, H., Sydney, S., Langlotz, T. and Aldridge, C. (2016). Social Presence and mode of video-communication in a collaborative virtual environment.

Allport, F. H. (1920). The influence of the group upon association and thought. Journal of Experimental Psychology, 3 (3), 159-182.

Anderson, T. (2009). Online instructor immediacy and instructor-student relationships in Second Life. In C. Wankel \& J. Kingsley (Eds.), Higher education in virtual worlds: teaching and learning in second life. Bingley: Emerald.

Baumeister, R. F. (2010). The self-advanced social psychology: The state of the science, 139-175.

Braidotti, R. (1996). Cyberfeminism with a difference. Futures of critical theory: Dreams of difference, 239-259.

Boon, S., \& Sinclair, C. (2009). A world I don't inhabit: Disquiet and identity in Second Life and Facebook. Educational Media International, 46(2), 99-110.

Bottero, W. (2010). Inter-subjectivity and Bourdieusian approaches to 'identity. Journal of Cultural Sociology, $4(1), 3-22$

Cahm, C. (2002). Kropotkin: And the Rise of Revolutionary Anarchism, 1872-1886. Cambridge University Press.

Corlett, J. A. (Ed.). (2016). Equality and liberty: Analyzing Rawls and Nozick. Springer.

Cresswell, J. (2009). Research design: Qualitative, quantitative, and mixed methods approaches. Thosands Oaks, CA: Sage.

DeLeon, A. (2008). Oh no, not the "A" word! Proposing an "anarchism" for education. Journal of Educational Studies, 44(2), 122-141.

Dohn, N. B. (2014). Implications for networked learning of the 'practice'side of social practice theories: A tacitknowledge perspective. In The design, experience and practice of networked learning (pp. 29-49). Springer International Publishing.

Edmundson, A. (2007). The Cultural Adaptation Process (CAP) Model: Designing E-Learning for Another Culture. In A. Edmundson (Ed.), Globalized E-Learning Cultural Challenges (pp. 267-290). Hershey PA: Information Science Publishing.

Ellul, J., \& Illich, I. (1995). Statements. Technology in Society, 17(2), 231-238.

Foucault, M. (1988). Technologies of the self. In Technologies of the self: A seminar with Michel Foucault (pp. 16-49).

Giddens, A (1991) Modernity and self-identity, Cambridge: Polity Press

Glenn, M., \& D'Agostino, D. (2008). The future of higher education: How technology will shape learning. New Media Consortium.

Greer, L. L., \& van Kleef, G. A. (2010). Equality versus differentiation: the effects of power dispersion on group interaction. Journal of Applied Psychology, 95(6), 1032.

Griffiths, M. (1995). Feminisms and the self. The web of identity. Routledge, London.

Haggis, T. (2009). What have we been thinking of? A critical overview of 40 years of student learning research in higher education. Studies in Higher Education, 34(4), 377-390.

Hodder, I. (Ed.). (2013). The meanings of things: material culture and symbolic expression. Routledge.

Hodgson, V., McConnell, D., \& Dirckinck-Holmfeld, L. (2012). The theory, practice and pedagogy of networked learning. In Exploring the theory, pedagogy and practice of networked learning (pp. 291-305). Springer New York.

Hoyt, A. (2013). Making Sense of Anarchism: Errico Malatesta's Experiments with Revolution, 1889-1900. Anarchist Studies, 21(2), 125-128.

Jackson, D., \& Temperley, J. (2007). From professional learning community to networked learning community. Professional learning communities: Divergence, depth and dilemmas, 45-62.

Kahler, M. (Ed.). (2015). Networked politics: agency, power, and governance. Cornell University Press.

Katz, S., \& Earl, L. (2010). Learning about networked learning communities. School effectiveness and school improvement, 21(1), 27-51.

Kropotkin, P. (2002). Anarchism: A collection of revolutionary writings. Courier Corporation.

Lave, J. (2009). The practice of learning. Contemporary theories of learning, 200-208. 
Lury, C (1998) Prosthetic culture, London: Routledge

MacKeogh, K., \& Fox, S. (2009). Strategies for embedding e-learning in traditional universities: drivers and barriers. Electronic Journal of E-learning, 7 (2), 147-154.

Marshall, P. (1993). Demanding the impossible: A history of anarchism. London, Fontana.

May, T. (1994). The political philosophy of poststructuralist anarchism. Pennsylvania, Pennsylvania State University Press.

McNay, L. (2013). Foucault and feminism: Power, gender and the self. John Wiley \& Sons.

Mueller, J. (2012). Anarchism, the state, and the role of education. Anarchist pedagogies: Collective actions, theories, and critical reflections on education, 14-31.

O'regan, K. (2003). Emotion and e-learning. Journal of Asynchronous Learning Networks, 7(3), 78-92.

Parker, I., \& Shotter, J. (Eds.). (2015). Deconstructing social psychology (Vol. 21). Psychology Press.

Portwood-Stacer, L. (2010). Constructing anarchist sexuality: Queer identity, culture, and politics in the anarchist movement. Sexualities, 13(4), 479-493.

Ryberg, T., \& Larsen, M. C. (2008). Networked identities: understanding relationships between strong and weak ties in networked environments. Journal of Computer Assisted Learning, 24(2), 103-115.

Savin-Baden, M., \& Sinclair, C. (2011). Lurking on the threshold: Being learners in silent spaces. In R. Land \& S. Bayne (Eds.), Digital differences. Rotterdam: Sense.

Stirner, M. (2012). The ego and his own: the case of the individual against authority. Courier Corporation.

Suoranta, J. (2011). Learners and oppressed peoples of the World, Wikify! Malott, C.

Trauger, A. (2009). Social agency and networked spatial relations in sustainable agriculture. Area, 41(2), 117-128.

Turner, Y. (2009). "Knowing me, knowing you," Is there nothing we can do? Pedagogic challenges in using group work to create an intercultural learning space. Journal of Studies in International Education, 13(2), 240-255.

Vuković, K. P. (2015). Free information: Networked learning utopia. In Critical Learning in Digital Networks (pp. 37-55). Springer International Publishing.

Wetherell, M. (2008). Subjectivity or psycho-discursive practices? Investigating complex intersectional identities. Subjectivity, 22(1), 73-81.

Wood, A., \& Smith, M. (2005). Online communication: linking technology, identity, and culture (2nd ed.). London: Lawrence Erlbaum.

Anietie Ukpabio, BSc (Hons), MSc, MBA, Cert Ed, MABE, MBCS, QTLS, FHEA I am a PhD Researcher at Lancaster University and a certified Business Analyst at IBM Client Innovation Centre.

My major interest posits in conducting research into the connections between our material surroundings, the technologies (beyond computers) that permeate them, and the ways we act, think and learn. Two recurring interests are how institutions design and evaluate their built environment domain to support opportunities for learning. More general interests include Activity Theory, networked and collaborative learning. Additionally, I also am concerned with collaborative work and group discussion in digitally-mediated environments, with a theoretical and practical commitment to social justice and equity within learning communities. I am interested in understanding the ways that sociocultural and sociotechnical elements inherent in applications of digital education operate to marginalise students who fall outside the ideations of dominant ideology.

My major qualifications are a first class honours degree in Computing from the University of Greenwich, an MSc. distinction in Information Technology from the Cardiff Metropolitan University, an MBA from University of Northampton. Apart from my previous software and IT industry experience, I am also a qualified teacher and my previous teaching background involves being a former Computing Lecturer at East Kent College, New Vic College and City College Norwich.

Acknowledgement: This research was undertaken as part of the PhD in E-research and Technology Enhanced Learning in the Department of Educational Research at Lancaster University. I am pleased to acknowledge the contribution of lecturers and peers in supporting the development of this study and its report as an assignment paper. 